\title{
국가대표 펜싱선수의 종목에 따른 체격 및 체력 비교 연구
}

\author{
정진(욱 ${ }^{1)} \cdot$ 김태완 $^{1)} \cdot$ 우승석 ${ }^{2)} \cdot$ 이 온 $^{2 *}$
}

1) 한국스포츠개발원 2) 서울대학교

\begin{abstract}
Jin-Wook Chung · Tae-Whan Kim · Seung-Seok Woo · On Lee. Examination of Physique and Fitness in Elite National Fencing Athletes. KINESIOLOGY, 2016, 18(2): 19-31. [PURPOSE] The purpose of this study was to examine physique and fitness in elite national fencing players. [METHODS] A total of 559 athletes who played as national players over 10 years participated in the study. There were 285 male and 274 female players (saber: 85 males, 93 females; epee: 105 males, 90 females; fleuret: 95 males, 91 females). Separate one-way ANOVA was performed to determine between sex and weapon categories. [RESULTS] There was a large difference between weapon categories in the male players more than in female players. Epee athletes were of largest physique (height, weight, and fat free mass), and the following were the order saber, and fleuret in both sex. Male epee athletes were significantly stronger in muscular strength and isokinetic muscular strength while female fleuret athletes were in power endurance, muscle endurance, and anaerobic power. Sabre athletes were significantly strong in muscular strength. Epee athletes were significantly strong in flexibility. [CONCLUSIONS] These results suggest that different physique and fitness factors in weapon categories require individualized training protocols.
\end{abstract}

Key words : elite national fencing athletes, physique, fitness, examination 주요어 : 국가대표 펜싱선수, 체격, 체력, 비교연구

\section{서론}

펜싱경기는 서양의 검술이 스포츠로 발전한 경기로 서 $105 \sim 110 \mathrm{~cm}$ 의 길이와 $500 \mathrm{~g} 700 \mathrm{~g}$ 의 철로 특수 제작 된 검을 이용하여 상대방에게 공격당하지 않으면서 상대방을 공격하는 '공격에 대한 수비에 중점을 둔 스포츠'이다. 펜싱경기는 공격의 유효면과 사용되는 검 또는 공격 방법 등의 경기 규칙에 따라 크게 플뢰 레(Foil), 에페(Epee), 사브르(Sabre) 3가지 종목으로 구 분된다(Roi \& Bianchedi, 2008).

플뢰레는 공격의 유효면이 몸통에만 제한된 경기로 공격과 방어권이 엄격히 구분되어 있고 공격 행동은 오 직 검 끝(Pointe)으로 찌르기만 가능한 경기이다. 사브 르는 제일 과격하고 속도가 빠른 것이 특징인 경기로 공격의 유효면이 상반신 전체이며, $105 \mathrm{~cm}$ 의 상대적으 로 짧은 검으로 찌르기와 검의 날과 등으로 베기가 가 능한 종목이다. 에페는 공격의 유효면이 전신이며, 플뢰 레와 마찬가지로 찌르기만 가능한 경기로 공격과 방어
의 구분 없이 상대방을 신속하게 찔러 득점을 해야 하 는 경기이다(Kim, 2011). 이렇듯 펜싱경기는 세부종목의 특성에 따라 요구되는 체격 및 체력요인의 특이성을 갖 게 되며, 이러한 특이성을 분석하는 것은 대부분의 스 포츠에서와 같이 향후 엘리트 선수들의 경기력 향상과 우수한 선수를 발굴하는데 도움이 된다(Kim \& Park, 1995; Mun et al., 1998; Trajković et al., 2011).

플뢰레, 에페, 사브르 이 세 가지 펜싱경기는 동일 하게 $12 \sim 14 \mathrm{~m}$ 의 길이와 $1.8 \sim 2 \mathrm{~m}$ 너비의 좁은 펜싱코트 (Piste)에서 두 선수가 거리를 좁혀 $1 / 25$ 초의 터치로 선 공격을 가해 득점해야 하며, 실점이 되지 않도록 빠르게 방어를 하는 경기이기 때문에 빠른 판단력과 민첩성이 요구된다(Barth \& Beck, 2007). 또한, 15점 또는 3분 3회전에 의해 승패가 결정되기 때문에 짧은 시간 동안 폭발적인 힘을 발휘하는 무산소성 파워가 매우 중요하며, 안정적인 중심이동과 순간적인 파워를 발휘하기 위해 하체의 근육이 발달하여 펜싱 선수들 의 하체 둘레가 일반인보다 크다고 보고되고 있다

\footnotetext{
*교신저자: fair98@snu.ac.kr
} 
(Shin et al., 2006). 선행연구에 따르면 펜싱선수가 비 선수 집단과 비교하면 신장과 체격이 크고 검을 쥐고 상대방의 유효면을 빠르게 찌르거나 베는 상체의 공 격 동작 때문에 우세한 팔의 악력과 주관절의 등속성 근파워 $\left(180^{\circ} / \mathrm{sec}\right)$ 및 근지구력 $\left(240^{\circ} / \mathrm{sec}\right)$ 이 높다고 보 고하였으며(Woo et al., 1997), 공격을 가하는 순간 검 을 더 멀리 뺃어 공격 거리를 확보하기 위한 상, 하체 의 신전능력과 어깨, 팔꿈치, 엉덩이, 무릎 관절 등 신 체 분절의 협응력이 중요하다고 보고하였다(Oh et al., 2013). 이와 더불어 최근 엘리트 펜싱 선수들의 수행 능력과 관련된 체력요인을 종합 분석한 연구결과 엘 리트 선수들의 체격이 준-엘리트 선수들에 비해 크며, 민첩성과 순발력과 연관된 기술 체력의 경우 엘리트 선수들이 준-엘리트 선수들과 비교하면 우수한 것으 로 나타났다(Turner et al., 2014).

한국 펜싱은 최근 스포츠 과학의 발전을 바탕으로 과학적인 트레이닝을 통한 기술 수행력이 향상되면서 점차 세계무대에서 두각을 나타내기 시작하였다. 2012 년 런던올림픽에서 금메달 2개, 은메달 1 개, 동메달 3 개를 획득하여 전 종목 메달 획득이라는 전례 없는 실적을 달성하였다(Kim, 2012). 또한, 최근 개최된 2014년 인천 아시안 게임에서도 금메달 8개, 은메달 6 개, 동메달 3 개로 총 17 개의 메달을 획득하면서 펜싱 종합 1 위라는 아시아 최고 자리를 차지하게 되었다.

그러나 이러한 국제대회 및 올림픽에서 우수한 성 적과는 상반되게도, 펜싱에 관한 국내 연구는 다른 종 목에 비해 부족한 실정이다. 현재 펜싱에 관한 국내 선행연구를 살펴보면 기술 향상을 위한 분석(Kim et al., 2004; Shin et al, 2003; Kim, 2010) 및 영상분석 (Park et al., 2011; Oh et al., 2013) 등 기술에 관한 주제들이 대부분을 차지하고 있다. 그러나 외국의 경 우 펜싱의 세부종목에 따른 체형 및 신체조성의 차이 (Sterkowicz-Przybycien, 2009), 상-하지의 등속성 및 플라이오메트릭 훈련의 효과(Tsolakis et al., 2011) 등 체격 및 체력이나 청각장애인을 대상으로 펜싱 코칭 에 대한 연구(Ulrich et al., 2012) 등 폭넓은 주제에 관해서 많은 연구가 진행되었다.

따라서 본 연구에서는 승패를 가름하는 결정적 요 인이며, 우수 선수를 선발하는 평가 기준에도 중요한 요건으로 간주하고 있는 체격과 체력 요인을 성별로
구분하여 종목별로 비교 분석하는데 있다.

\section{연구 방법}

\section{연구대상}

이 연구의 실험 대상자는 1999년부터 2015년까지 펜싱 국가대표선수로 활동하였으며 한국스포츠개발원 에서 체력측정을 시행한 엘리트 펜싱선수 559명(남자 285 명, 여자 274명)으로 각각 사브르 178 명(남자 85명, 여자 93명), 에페 195명(남 105명, 여 90명), 플뢰레 186명(남 95명, 여 91명)을 대상으로 하였다. 종목과 성별에 따른 일반적 특성은 <Table 1 >과 같다.

Table 1. Physical characteristic of subjects

$(\mathrm{M} \pm \mathrm{SD})$

\begin{tabular}{|c|c|c|c|c|}
\hline & & Age & Hight $(\mathrm{cm})$ & Weight(kg) \\
\hline \multirow{3}{*}{ male } & Sabre $(\mathrm{n}=85)$ & $24.41 \pm 3.90$ & $180.69 \pm 3.86$ & $73.81 \pm 7.19$ \\
\hline & Epee( $(\mathrm{n}=105)$ & $25.95 \pm 3.88$ & $181.69 \pm 4.64$ & $77.80 \pm 7.61$ \\
\hline & Foil $(\mathrm{n}=95)$ & $24.58 \pm 3.16$ & $177.33 \pm 5.47$ & $72.11 \pm 7.12$ \\
\hline & Sabre $(n=93)$ & $22.39 \pm 2.65$ & $166.50 \pm 3.97$ & $60.10 \pm 5.23$ \\
\hline emale & Epee & $23.78 \pm 3.49$ & $168.91 \pm 4.38$ & $62.25 \pm 5.16$ \\
\hline & Foil $(\mathrm{n}=91)$ & $24.10 \pm 3.73$ & $165.88 \pm 6.34$ & $57.15 \pm 6.70$ \\
\hline
\end{tabular}

본 연구에서는 일부 선수에서 반복 측정이 이루어 졌으나, 각 측정횟수 모두를 사례 수로 간주하였다. 이는 국가대표 선수의 경우 특정 기간 동안 종목을 대표하는 대상자이며, 국가대표 선수의 체력자료로서 의 가치를 지니고 있기 때문이다. 남자 대상자는 97명 으로 평균 2.94회의 중복이 있고 여자 대상자는 94 명으 로 평균 2.91회의 중복이 있으며 최대 중복횟수는 남녀 모두 10회였다.

\section{실험설계 및 절차}

측정항목은 펜싱선수들의 체격요인(길이, 무게, 둘 레)과 종목별 특성이 고려된 체력을 중심으로 측정하 였다. 구체적인 항목은 < Table 2>와 같다.

일반적인 항목들의 측정방법은 표준화된 방법을 이 용하여 측정하였으며, 연습할 기회를 제공하고 2회를 측정하여 좋은 기록을 선택하였다. 등속성 각근력과 각근파워는 등속성 근력측정시스템(Cybex)를 이용하 
Table 2. Variables of physique and fitness

\begin{tabular}{ll}
\hline \multicolumn{1}{c}{ Fitness } & \multicolumn{1}{c}{ Variables } \\
\hline \hline composition & $\begin{array}{l}\text { Weight/Percent Body Fat/Body } \\
\text { mass index/Fat free Mass }\end{array}$ \\
\hline Length & $\begin{array}{l}\text { Height/Arm span/Sitting } \\
\text { height/Chest depth }\end{array}$ \\
\hline Circumference & Thigh/Lower leg/Arm/Forearm \\
\hline $\begin{array}{l}\text { Cardiopulmonary } \\
\text { function }\end{array}$ & $\begin{array}{l}\text { Forced vital capacity /Forced } \\
\text { expiratory volume in one } \\
\text { second/Resting heart rate }\end{array}$ \\
\hline Muscular strength & $\begin{array}{l}\text { Back strength/ } \\
\text { Grip strength/Half-squat(1RM) }\end{array}$ \\
\hline Muscle endurance & Repetition jump(30cm)/Sit-up \\
\hline Agility & $\begin{array}{l}\text { Side-step/Back and forth-step/ } \\
\text { Change-step jump/Reaction time } \\
\text { (light/sound) }\end{array}$ \\
\hline Power & standing long jump \\
\hline Flexibility & $\begin{array}{l}\text { Trunk extension/Sitting trunk } \\
\text { forward flexion/leg span(front } \\
\text { and back, side and side) }\end{array}$ \\
\hline Balance & $\begin{array}{l}\text { standing on one leg with eyes } \\
\text { closed/Dynamic balance }\end{array}$ \\
\hline Isokinetic knee strength Flexion(Nm)/Extension(Nm) \\
\hline Anaerobic ability & \begin{tabular}{l} 
Maximal power/Average power \\
\hline
\end{tabular}
\end{tabular}

였으며 각근력은 $60 \%$ sec에서 각각 3회의 측정을 하 여 값을 산출하였다. 무산소성능력은 윈게이트를 이용 하여 측정하였다. 기타 생소할 수 있는 측정방법을 설 명하면 다음과 같다.

\section{등장성 최대근력}

등장성 최대근력은 하프 스쿼트, 배근력, 악력을 측정 하였다. 그 중 하프 스쿼트는 ACE-2000 Multi-Function( Ariel Dynamics INC., USA)를 이용하여 하프 스쿼트 동작에서 최대로 발휘하는 힘을 측정하기 위해서 실시 하였으며, 피험자가 2 3회 들어 올릴 수 있는 무게를 설정하여 최대의 힘으로 힘껏 동작을 취해 나타나는 결과를 동적 근력인 $1 \mathrm{RM}$ 으로 결정하였다. 결과값은 들어 올린 중량 $(\mathrm{kg})$ 으로 기록하였다. West(2011)는 하 프 스쿼트와 같은 등장성 최대근력이 펜싱선수의 경기 력을 예측하는 데 의미있는 체력요인이라고 하였다.

\section{0초간 발바꿔뛰기}

민첩성을 측정하기 위하여 30초간 발바꿔뛰기를 실시 하였다. 이는 가로세로 $30 \mathrm{~cm}$ 정사각형에서 전후, 좌우로 발을 정확하고 빠르게 교차하여 30 초간 움직인 것을 측 정한다. 정사각형 밖으로 발이 벗어났다가 다시 발이 모
이는 것을 1 회로 간주한다. 발이 정확하게 정사각형 밖 으로 나갔다가 정사각형 안으로 모여야 개수를 인정하 였다. 30초간 발바꿔뛰기는 민첩성, 지구성, 균형능력을 측정할 수 있는 측정 방식으로 배드민턴과 같은 라켓 종목 선수들에게 많이 적용되고 있다(Kim et al., 2007).

\section{반복점프 $(30 \mathrm{~cm})$}

근지구력을 측정하기 위해 반복점프 $(30 \mathrm{~cm})$ 를 측정 하였다. 반복점프 $(30 \mathrm{~cm})$ 는 해부학적 자세에서 팔만 들 어 올려 중지의 손끝을 기준으로 하여 60 초 동안 $30 \mathrm{~cm}$ 이상의 높이에 있는 선을 점프하면서 손으로 닫는 횟수를 기록한다. 손끝의 위치가 정확히 범위 안 에 들어오는 것을 1 회로 간주하였다. 반복점프는 특히 하지(대퇴부 \& 종아리)의 근지구력을 측정하는 방법 이지만, 실제 측정시 상지근육과 함께 동원되어 전신 지구력을 대표하는 측정방식이다(Kim et al., 2007).

\section{하지 전휘좌우 개각}

하지의 유연성을 측정하기 위해 하지 전후개각과 하지 좌우개각을 실시하였다. 하지전후개각의 측정 방 법은 무릎을 완전히 편 상태로 양발 11자를 유지하여 최대한 앞뒤로 벌려 최대각도를 각도기로 측정하였다. 하지좌우개각의 측정 방법은 상체를 펴서 바른 자세로 유지한 채 무릎을 펴고 양발을 최대한 양옆으로 뻗게 하여 최대각도 $\left({ }^{\circ}\right)$ 를 측정하였다. 총 2회 실시하였으며 최고치를 기록하였다. 이와 같은 하지 전후/좌우 개각 은 펜싱의 다양한 기술 수행과 밀접한 연관성으로 경 기력을 예측할 수 있는 요소이다(Cronin et al., 2003).

\section{동적 평형성}

평형성을 측정하기 위해 실시하였으며, 움직임이 심한 측정판 위에서 중심을 잡고 서 있는 상태를 측 정하였다. 1 분의 측정시간 중 설정된 각도 범위 내에 서 유지한 시간을 초 단위로 기록하였다.

\section{자료처리}

본 연구에서 측정한 모든 변인의 값은 SPSS 18.0 통계 프로그램을 이용하여 평균과 표준편차를 제시하 였다. 성별을 구분하여 종목별 체격 및 체력의 차이를 
확인하기 위하여 일원 배치분산분석(ANOVA)을 실시 하였으며 사후검정(post hoc test)은 LSD를 사용하였 다. 모든 통계검증의 유의수준은 $a=.05$ 로 설정하였다.

\section{결과}

\section{신체구성}

남녀 펜싱선수들의 신체구성을 측정한 결과는 <Table 3>과 같다. 남자 펜싱선수들은 체중, 체지방 률, $\mathrm{BMI}$, 제지방 체중에서 모두 에페 선수들이 사브 르와 플뢰레 선수들보다 유의하게 높은 것으로 나타 났으며, 여자 선수들의 경우 체중은 플뢰레, 사브르, 에페 순으로 높게 나타났으며, 체지방률과 BMI는 플 뢰레가 사브르나 에페보다 유의하게 낮은 것으로, 제 지방 체중은 사브르와 에페는 차이가 없고 플뢰레는

\section{Table 3. Comparison of Body composition in sword} category and gender

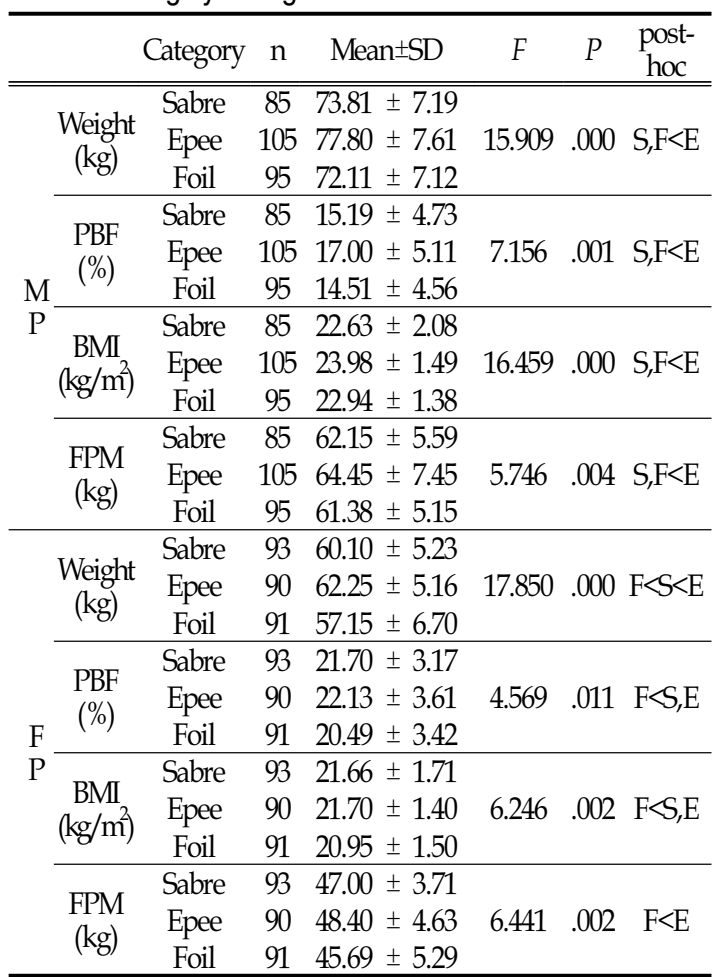

MP: male fencing player, FP: female fencing player, S: Sabre, E: Epee, F: Foil, PBF: Percent Body Fat, BMI: Body mass index, FPM Fat free Mass
유의하게 적은 것으로 나타났다.

\section{길이}

남녀 펜싱선수들의 길이를 측정한 결과는 <Table $4>$ 와 같다. 남자 펜싱선수들의 경우 신장, 지극, 좌고 에서는 사브르와 에페가 플뢰레 보다 유의하게 높은 것으로 나타났으며, 흉곽전후폭은 에페가 플뢰레보다 큰 것으로 나타났다. 여자 선수들의 경우 신장과 하지

Table 4. Comparison of dominant body length in sword category and gender unit(cm)

\begin{tabular}{|c|c|c|c|c|c|c|c|}
\hline & & Category & $\mathrm{n}$ & Mean \pm SD & $F$ & $P$ & $\begin{array}{l}\text { post- } \\
\text { hoc }\end{array}$ \\
\hline & & Sabre & 85 & $180.59 \pm 4.98$ & & & \\
\hline & Hight & Epee & 105 & $180.39 \pm 6.00$ & 11.855 & .000 & $\mathrm{~F}<\mathrm{S}, \mathrm{E}$ \\
\hline & & Foil & 95 & $177.07 \pm 5.59$ & & & \\
\hline & & Sabre & 59 & $184.64 \pm 8.55$ & & & \\
\hline & Arm & Epee & 84 & $184.21 \pm 7.35$ & 4.607 & .011 & $\mathrm{~F}<\mathrm{S}, \mathrm{E}$ \\
\hline & & Foil & 79 & $181.30 \pm 6.13$ & & & \\
\hline & & Sabre & 43 & $96.93 \pm 2.36$ & & & \\
\hline & Sitting & Epee & 63 & $97.99 \pm 3.74$ & 12.555 & .000 & $\mathrm{~F}<\mathrm{S}, \mathrm{E}$ \\
\hline M & & Foil & 68 & $94.64 \pm 4.73$ & & & \\
\hline $\mathrm{P}$ & & Sabre & 59 & $19.91 \pm 2.65$ & & & \\
\hline & Chest & Epee & 87 & $20.67 \pm 2.37$ & 5.319 & .006 & $\mathrm{~F}<\mathrm{E}$ \\
\hline & & Foil & 81 & $19.33 \pm 2.99$ & & & \\
\hline & & Sabre & 60 & $79.56 \pm 3.28$ & & & \\
\hline & Arm & Epee & 84 & $79.13 \pm 3.42$ & 2.869 & .059 & \\
\hline & & Foil & 80 & $78.89 \pm 3.69$ & & & \\
\hline & & Sabre & 60 & $93.59 \pm 3.93$ & & & \\
\hline & Leg & Epee & 84 & $93.45 \pm 3.66$ & 2.387 & .094 & \\
\hline & & Foil & 80 & $92.35 \pm 3.83$ & & & \\
\hline & & Sabre & 93 & $166.48 \pm 2.75$ & & & \\
\hline & Hight & Epee & 90 & $169.14 \pm 4.60$ & 16.297 & .000 & $\mathrm{~S}, \mathrm{~F}<\mathrm{E}$ \\
\hline & & Foil & 91 & $165.08 \pm 5.93$ & & & \\
\hline & & Sabre & 69 & $167.00 \pm 19.15$ & & & \\
\hline & Arm & Epee & 70 & $170.70 \pm 5.59$ & 1.873 & .156 & \\
\hline & & Foil & 69 & $167.62 \pm 6.43$ & & & \\
\hline & & Sabre & 63 & $89.87 \pm 3.36$ & & & \\
\hline & Sitting & Epee & 60 & $90.73 \pm 2.57$ & 4.818 & .009 & $\mathrm{~F}<\mathrm{E}$ \\
\hline $\mathrm{F}$ & & Foil & 58 & $88.99 \pm 3.10$ & & & \\
\hline $\mathrm{P}$ & & Sabre & 63 & $17.66 \pm 1.85$ & & & \\
\hline & Chest & Epee & 74 & $18.01 \pm 1.93$ & .564 & .570 & \\
\hline & & Foil & 64 & $17.76 \pm 2.25$ & & & \\
\hline & & Sabre & 49 & $72.62 \pm 2.75$ & & & \\
\hline & Arm & Epee & 70 & $73.38 \pm 2.98$ & 4.150 & .017 & $\mathrm{~F}<\mathrm{E}$ \\
\hline & & Foil & 69 & $71.79 \pm 3.92$ & & & \\
\hline & & Sabre & 69 & $86.62 \pm 3.63$ & & & \\
\hline & $\begin{array}{l}\text { Leg } \\
\text { lenoth }\end{array}$ & Epee & 70 & $88.65 \pm 2.94$ & 9.421 & .000 & $\mathrm{~F}, \mathrm{~S}<\mathrm{E}$ \\
\hline & & Foil & 69 & $86.14 \pm 4.19$ & & & \\
\hline
\end{tabular}

MP: male fencing player, FP: female fencing player, S: Sabre, E: Epee, F: Foil 
장은 에페 선수들이 사브르나 플뢰레보다 큰 것으로 나타났으며, 좌고와 상지장은 에페가 플뢰레보다 큰 것으로 나타났다.

\section{둘레}

남녀 펜싱선수들의 주측 둘레를 측정한 결과는 <Table 5>와 같다. 남자 펜싱 선수들은 전완위를 뺀 나머지 변인에서 모두 에페 선수들의 사브르나 플뢰 레 선수들보다 둘레가 큰 것으로 나타났다. 여자 선수 들은 흥위에서는 에페가 사브르와 플뢰레보다 크고 대퇴위와 전완위는 사브르와 에페가 플뢰레보다 유의 하게 큰 것으로 나타났다.

Table 5. Comparison of dominant body circumference in sword category and gender unit(cm)

\begin{tabular}{|c|c|c|c|c|c|c|c|}
\hline & & $\begin{array}{c}\text { Categor } \\
\mathrm{y}\end{array}$ & $\mathrm{n}$ & Mean $\pm S D$ & $F$ & $P$ & $\begin{array}{l}\text { post- } \\
\text { hoc }\end{array}$ \\
\hline & & Sabre & 72 & $90.83 \pm 4.84$ & & & \\
\hline & Chest & Epee & 92 & $93.64 \pm 5.90$ & 10.512 & .000 & $\mathrm{~S}, \mathrm{~F}<\mathrm{E}$ \\
\hline & & Foil & 91 & $90.23 \pm 5.05$ & & & \\
\hline & & Sabre & 74 & $59.63 \pm 3.81$ & & & \\
\hline & Thigh & Epee & 98 & $61.36 \pm 3.04$ & 9.534 & .000 & $\mathrm{~S}, \mathrm{~F}<\mathrm{E}$ \\
\hline & & Foil & 95 & $59.47 \pm 3.09$ & & & \\
\hline & & Sabre & 84 & $32.96 \pm 12.54$ & & & \\
\hline & Lower & Epee & 105 & $35.93 \pm 9.87$ & 5.944 & .003 & $\mathrm{~S}<\mathrm{F}, \mathrm{E}$ \\
\hline & & Foil & 95 & $37.64 \pm 1.72$ & & & \\
\hline & & Sabre & 74 & $29.09 \pm 2.30$ & & & \\
\hline & Arm & Epee & 98 & $30.21 \pm 2.02$ & 6.603 & .002 & $\mathrm{~S}, \mathrm{~F}<\mathrm{E}$ \\
\hline & & Foil & 95 & $29.62 \pm 1.74$ & & & \\
\hline & & Sabre & 74 & $27.18 \pm 1.40$ & & & \\
\hline & & Epee & 98 & $27.69 \pm 1.93$ & 2.394 & .320 & \\
\hline & & Foil & 95 & $27.30 \pm 1.45$ & & & \\
\hline & & Sabre & 92 & $84.11 \pm 4.34$ & & & \\
\hline & Chest & Epee & 82 & $85.44 \pm 3.53$ & 3.904 & .021 & $\mathrm{~S}, \mathrm{~F}<\mathrm{E}$ \\
\hline & & Foil & 88 & $83.79 \pm 4.22$ & & & \\
\hline & & Sabre & 91 & $59.56 \pm 2.72$ & & & \\
\hline & Thigh & Epee & 85 & $58.29 \pm 2.98$ & 18.556 & .000 & $\mathrm{~F}<\mathrm{S} . \mathrm{E}$ \\
\hline & & Foil & 91 & $56.03 \pm 3466$ & & & \\
\hline & & Sabre & 95 & $34.29 \pm 7.45$ & & & \\
\hline $\begin{array}{l}F \\
p\end{array}$ & Lower & Epee & 90 & $34.09 \pm 8.41$ & .181 & .834 & \\
\hline & & Foil & 91 & $34.68 \pm 2.38$ & & & \\
\hline & & Sabre & 91 & $27.75 \pm 21.30$ & & & \\
\hline & Arm & Epee & 85 & $25.92 \pm 1.90$ & 1.000 & .369 & \\
\hline & & Foil & 91 & $25.19 \pm 1.81$ & & & \\
\hline & & Sabre & 91 & $23.43 \pm 0.95$ & & & \\
\hline & & Epee & 85 & $23.78 \pm 1.29$ & 9.278 & .000 & $\mathrm{~F}<\mathrm{S}, \mathrm{E}$ \\
\hline & & Foil & 91 & $22.97 \pm 1.47$ & & & \\
\hline
\end{tabular}

MP: male fencing player, FP: female fencing player, S: Sabre, E: Epee, F: Foil

\section{심폐기능}

펜싱선수들의 심폐기능을 측정한 결과는 <Table $6>$ 과 같다. 남자 선수들의 경우, 1 초량에서 사브르와 에뻬가 플뢰레에 비해 높은 것으로 나타났으며, 여자 선수들은 심폐기능 모든 변인에서 세부 펜싱 종목별 유의한 차이가 없었다.

Table 6. Comparison of Cardiopulmonary function in sword category and gender

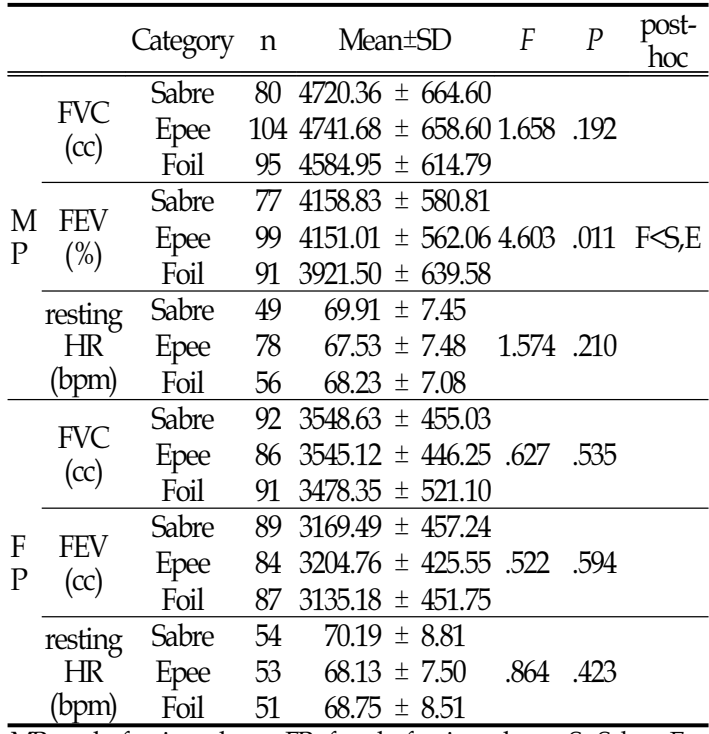

MP: male fencing player, FP: female fencing player, S: Sabre, E: Epee, F: Foil, FVC: Forced vital capacity(cc), FEV: Forced expiratory volume in one second $(\%)$

\section{근력}

펜싱선수들의 근력을 측정한 결과는 <Table 7>과 같 다. 남자 펜싱선수들의 경우, 하프 스쿼트와 악력에서, 여자 선수들의 경우는 악력에서만 에페가 사브르와 플뢰 레와 비교하면 유의하게 높은 것으로 나타났다 $(p<.005)$.

\section{근지구력}

엘리트 남녀 펜싱선수들의 근지구력 측정결과는 <Table 8>과 같다. 남자 선수들의 경우 세부종목별 유의한 차이가 없었으나, 여자 선수들의 경우, 반복점 프 $30 \mathrm{~cm}$ 와 싯업에서 플뢰레가 다른 종목보다 유의하 
Table 7. Comparison of Muscular strength in sword category and gender unit $(\mathrm{kg})$

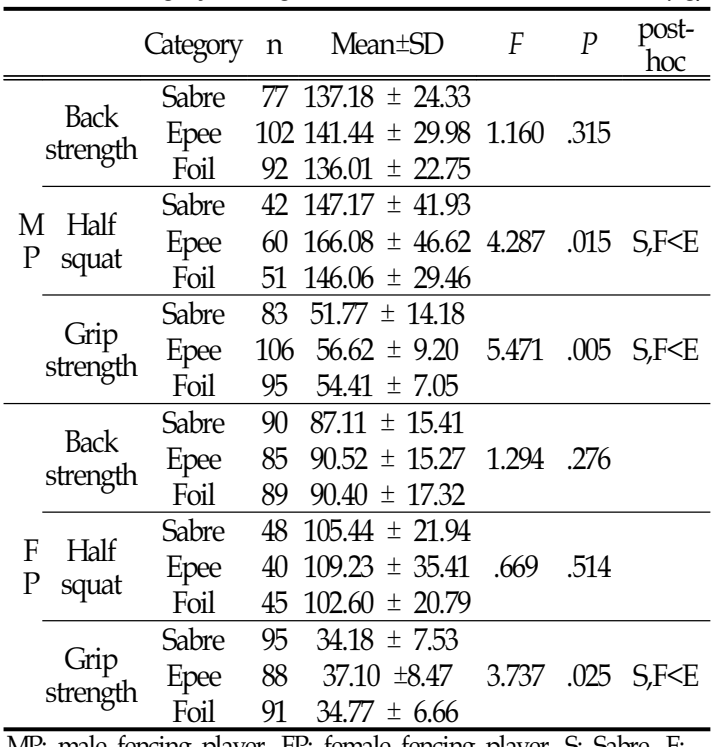

MP: male fencing player, FP: female fencing player, S: Sabre, E: Epee, F: Foil

Table 8. Comparison of Muscular endurance in sword category and gender unit (count/60s)

\begin{tabular}{|c|c|c|c|c|c|c|c|}
\hline & & Category & $\mathrm{n}$ & Mean \pm SD & F & $P$ & $\begin{array}{l}\text { post- } \\
\text { hoc }\end{array}$ \\
\hline \multirow{6}{*}{$\begin{array}{l}\mathrm{M} \\
\mathrm{P}\end{array}$} & Repetitio & Sabre & 41 & $84.85 \pm 17.48$ & \multirow{3}{*}{.836} & \multirow{3}{*}{.436} & \\
\hline & $\mathrm{n}$ jump & Epee & 58 & $89.71 \pm 18.89$ & & & \\
\hline & $(30 \mathrm{~cm})$ & Foil & 55 & $87.40 \pm 18.68$ & & & \\
\hline & & Sabre & 74 & $53.03 \pm 9.52$ & \multirow{3}{*}{.908} & \multirow{3}{*}{. 405} & \\
\hline & Sit-up & Epee & 101 & $51.81 \pm 9.48$ & & & \\
\hline & & Foil & 94 & $51.11 \pm 8.66$ & & & \\
\hline \multirow{6}{*}{$\begin{array}{l}F \\
P\end{array}$} & Repetitio & Sabre & 50 & $87.40 \pm 20.12$ & \multirow{3}{*}{8.607} & \multirow{3}{*}{.000} & \multirow{3}{*}{$E<S<F$} \\
\hline & $\mathrm{n}$ jump & Epee & 43 & $77.51 \pm 23.87$ & & & \\
\hline & $(30 \mathrm{~cm})$ & Foil & 48 & $97.21 \pm 23.90$ & & & \\
\hline & \multirow{3}{*}{ Sit-up } & Sabre & 90 & $47.22 \pm 7.51$ & \multirow{3}{*}{17.241} & \multirow{3}{*}{.000} & \multirow{3}{*}{$\mathrm{S}, \mathrm{E}<\mathrm{F}$} \\
\hline & & Epee & 83 & $46.10 \pm 8.11$ & & & \\
\hline & & Foil & 90 & $52.92 \pm 9.10$ & & & \\
\hline
\end{tabular}

MP: male fencing player, FP: female fencing player, S: Sabre, E: Epee, F: Foil

게 높은 것으로 나타났다( $p<.000)$.

\section{순발력}

펜싱선수들의 순발력은 제자리멀리뛰기로 측정하였 으며, 그 결과는 <Table 9>와 같으며, 남녀 펜싱선수 들 모두 세부 종목별 유의한 차이가 나타나지 않았다.
Table 9. Comparison of Power in sword category and gender

unit $(\mathrm{cm})$

\begin{tabular}{|c|c|c|c|c|c|c|}
\hline & Category & $\mathrm{n}$ & Mean $\pm S D$ & $F$ & $P$ & $\begin{array}{l}\text { post- } \\
\text { hoc }\end{array}$ \\
\hline \multirow{3}{*}{$\begin{array}{cc} & \text { standing } \\
\mathrm{P} & \text { long } \\
& \text { jump }\end{array}$} & Sabre & & $45.07 \pm 17.88$ & \multirow{3}{*}{.273} & \multirow{3}{*}{.762} & \\
\hline & Epee & 62 & $43.73 \pm 19.87$ & & & \\
\hline & Foil & & $42.25 \pm 17.99$ & & & \\
\hline \multirow{3}{*}{$\begin{array}{lc}\text { F } & \text { standing } \\
\mathrm{P} & \text { long } \\
& \text { jump }\end{array}$} & Sabre & & $.04 .37 \pm 15.74$ & \multirow{3}{*}{.032} & \multirow{3}{*}{.969} & \\
\hline & Epee & & $.03 .98 \pm 14.36$ & & & \\
\hline & Foil & & $05.03 \pm 23.94$ & & & \\
\hline
\end{tabular}

MP: male fencing player, FP: female fencing player

민첩성

펜싱선수들의 민첩성을 측정한 결과는 <Table 10> 과 같다. 민첩성에서는 여자 선수들의 30초간 발바꿔 뛰기에서만 플뢰레가 에페보다 빠른 것으로 나타났다.

Table 10. Comparison of Agility in sword category and gender

\begin{tabular}{|c|c|c|c|c|c|c|c|}
\hline & & Category & $n$ & Mean $\pm S D$ & $F$ & $P$ & $\begin{array}{l}\text { post- } \\
\text { hoc }\end{array}$ \\
\hline \multirow{15}{*}{$\begin{array}{l}\mathrm{M} \\
\mathrm{P}\end{array}$} & Side step & Sabre & 41 & $45.59 \pm 6.48$ & \multirow{3}{*}{.519} & \multirow{3}{*}{.596} & \\
\hline & (counts & Epee & 60 & $46.30 \pm 4.36$ & & & \\
\hline & $/ 20 s)$ & Foil & 56 & $45.38 \pm 4.68$ & & & \\
\hline & Back and & Sabre & 25 & $50.48 \pm 4.35$ & \multirow{3}{*}{3.024} & \multirow{3}{*}{.054} & \\
\hline & forth-step & Epee & 33 & $47.00 \pm 4.90$ & & & \\
\hline & $/ 20 \mathrm{~s})$ & Foil & 34 & $48.06 \pm 6.45$ & & & \\
\hline & \multirow{3}{*}{$\begin{array}{l}\text { Change } \\
\text { step } \\
\text { jump } \\
\text { (counts } \\
\text { /30s) }\end{array}$} & Sabre & 65 & $61.26 \pm 6.06$ & \multirow{3}{*}{.063} & \multirow{3}{*}{.939} & \\
\hline & & Epee & 98 & $61.20 \pm 7.35$ & & & \\
\hline & & Foil & 82 & $61.54 \pm 5.79$ & & & \\
\hline & \multirow{6}{*}{$\begin{array}{c}\text { Reaction } \\
\text { time } \\
\text { (light) } \\
\text { (s:191000) } \\
\text { Reaction } \\
\text { time } \\
\text { (light) } \\
\text { (s:191000) }\end{array}$} & Sabre & 51 & $0.273 \pm 0.03$ & \multirow{3}{*}{.120} & \multirow{3}{*}{.887} & \\
\hline & & Epee & 66 & $0.275 \pm 0.05$ & & & \\
\hline & & Foil & 61 & $0.271 \pm 0.05$ & & & \\
\hline & & Sabre & 21 & $0.239 \pm 0.03$ & \multirow{3}{*}{.703} & \multirow{3}{*}{.499} & \\
\hline & & Epee & 21 & $0.249 \pm 0.03$ & & & \\
\hline & & Foil & 23 & $0.240 \pm 0.03$ & & & \\
\hline \multirow{3}{*}{\multicolumn{2}{|c|}{$\begin{array}{c}\text { Side step } \\
\text { (counts } \\
\text { /20s) }\end{array}$}} & Sabre & 49 & $40.65 \pm 4.70$ & \multirow{3}{*}{.317} & \multirow{3}{*}{.729} & \\
\hline & & Epee & 45 & $41.11 \pm 4.93$ & & & \\
\hline & & Foil & 50 & $40.36 \pm 4.26$ & & & \\
\hline \multirow{12}{*}{$\begin{array}{l}F \\
P\end{array}$} & Back and & Sabre & 39 & $46.80 \pm 4.09$ & \multirow{3}{*}{.683} & \multirow{3}{*}{.507} & \\
\hline & $\begin{array}{l}\text { forth-step } \\
\text { (counts }\end{array}$ & Epee & 38 & $45.87 \pm 4.67$ & & & \\
\hline & $/ 20 \mathrm{~s})$ & Foil & 38 & $45.87 \pm 3.16$ & & & \\
\hline & Change & Sabre & 78 & $59.83 \pm 7.68$ & \multirow{3}{*}{3.315} & \multirow{3}{*}{.038} & \multirow{3}{*}{$\mathrm{E}<\mathrm{F}$} \\
\hline & step & Epee & 80 & $59.15 \pm 6.27$ & & & \\
\hline & $\begin{array}{l}\text { (counts } \\
\text { /30s) }\end{array}$ & Foil & 75 & $61.87 \pm 6.35$ & & & \\
\hline & Reaction & Sabre & 61 & $0.284 \pm 0.05$ & \multirow{3}{*}{.135} & \multirow{3}{*}{.969} & \\
\hline & time & Epee & 61 & $0.281 \pm 0.05$ & & & \\
\hline & (s:191000) & Foil & 64 & $0.284 \pm 0.05$ & & & \\
\hline & Reaction & Sabre & 34 & $0.263 \pm 0.03$ & \multirow{3}{*}{6.092} & \multirow{3}{*}{.368} & \\
\hline & $\begin{array}{c}\text { time } \\
\text { (light) }\end{array}$ & Epee & 31 & $0.263 \pm 0.03$ & & & \\
\hline & (s:1/1000) & Foil & 31 & $0.265 \pm 0.04$ & & & \\
\hline
\end{tabular}

MP: male fencing player, FP: female fencing player, S: Sabre, E: Epee, F: Foil 


\section{유연성}

펜싱선수들의 유연성을 측정한 결과는 <Table 11>과 같다. 남자 펜싱선수는 장좌체전굴에서 에페선수가 사브 르나 플뢰레 선수보다 유연한 것으로 나타났으며 $(p<.001)$, 발목 각도는 플뢰레가 사브르나 에페 선수보다 큰 것으 로 나타났다 $(p<.000)$. 여자 펜싱선수의 경우, 하지 좌우개 각에서 사브르 선수가 에페나 플뢰레 선수와 비교하면 덜 유연한 것으로 나타났으며( $p<.002)$, 발목각도는 플뢰 레가 사브르보다 유연한 것으로 나타났다( $p<.000)$.

\section{평형성}

펜싱선수들의 평형성 측정 결과는 <Table $12>$ 와

Table 11. Comparison of Fexibility in sword category and gender

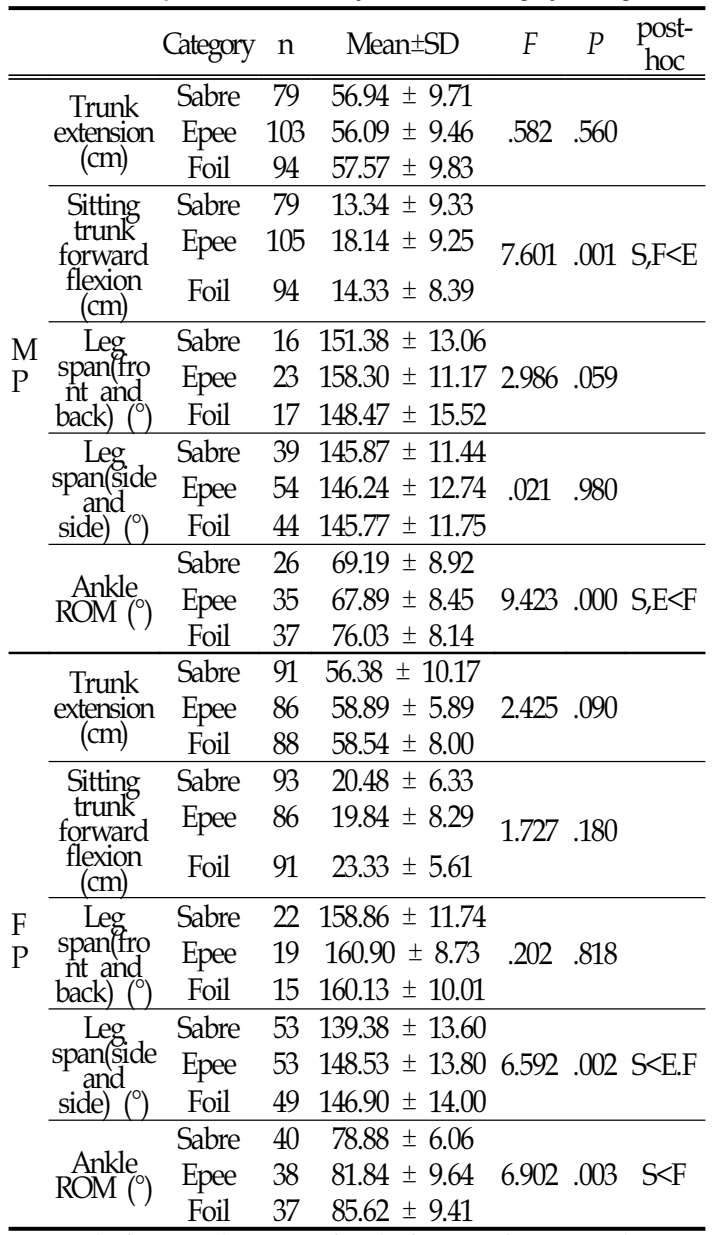

MP: male fencing player, FP: female fencing player, S: Sabre, E: Epee, F: Foil
Table 12. Comparison of Balance in sword category and gender unit (sec)

\begin{tabular}{|c|c|c|c|c|c|c|}
\hline & Category & $\mathrm{n}$ & Mean \pm SD & $F$ & $P$ & $\begin{array}{l}\text { post- } \\
\text { hoc }\end{array}$ \\
\hline standing & Sabre & 43 & $39.13 \pm 33.48$ & & & \\
\hline $\begin{array}{l}\text { on one } \\
\text { leg with }\end{array}$ & Epee & 66 & $40.38 \pm 34.27$ & 4.119 & .018 & $\mathrm{F}<\mathrm{S}, \mathrm{E}$ \\
\hline \multirow{4}{*}{$\begin{array}{c}\text { MP eyes close } \\
\begin{array}{c}\text { Dynamic } \\
\text { balance }\end{array}\end{array}$} & Foil & 51 & $25.26 \pm 19.50$ & & & \\
\hline & Sabre & 27 & $16.44 \pm 6.52$ & & & \\
\hline & Epee & 34 & $15.32 \pm 6.80$ & 2.041 & 136 & \\
\hline & Foil & 36 & $18.79 \pm 8.31$ & & & \\
\hline \multirow{3}{*}{$\begin{array}{l}\text { standing } \\
\text { on one } \\
\text { leg with } \\
\text { eyes close }\end{array}$} & Sabre & 42 & $54.32 \pm 33.98$ & & & \\
\hline & Epee & 45 & $51.31 \pm 44.91$ & .280 & .756 & \\
\hline & Foil & 41 & $47.53 \pm 44.20$ & & & \\
\hline \multirow{3}{*}{$\begin{array}{l}\text { FP Dynamic } \\
\text { balance }\end{array}$} & Sabre & 40 & $29.30 \pm 7.67$ & & & \\
\hline & Epee & 39 & $24.38 \pm 8.18$ & 4.318 & . 016 & $\mathrm{E}<\mathrm{S}, \mathrm{F}$ \\
\hline & Foil & 39 & $29.63 \pm 10.49$ & & & \\
\hline
\end{tabular}
MP: male fencing player, FP: female fencing player, S: Sabre, E: Epee, F: Foil

같다. 남자의 경우는 눈감고 외발서기에서 사브르와 에페선수들이 플뢰레보다 좋은 것으로 $(p<.018)$, 여자 선수에서는 동적 평형성에서 사브르와 플뢰레 선수들 이 에페 선수들보다 좋은 것으로 나타났다 $(p<.016)$.

\section{등속성 각근력 $\left(60^{\circ} / \mathrm{sec}\right)$}

펜싱선수들의 등속성 각근력을 측정한 결과는 <Table 13>과 같다. 남자 펜싱선수들의 경우 신근의 주측 $(p<.000)$, 보조측 $(p<.001)$, 굴근이 보조측 $(p<.004)$ 에서 사브르와 에빼 선수들의 플뢰레 선수들에 비해 유의하 게 높은 것으로 나타났으며, 굴근의 주측에서는 플뢰레 선수들이 에빼 선수들에 비해 유의하게 낮은 것으로 나타났다(p<.046). 여자 선수들의 경우는 굴근의 보조측 에서만 에빼 선수들이 사브르와 플뢰레 선수들에 비해 유의하게 높은 것으로 나타났다 $(p<.029)$. 주측과 보조측 의 비율은 남자선수의 신근에서 플뢰레 선수가 에빼 선수에 비해 유의하게 높은 것으로 나타났으며, 굴신비 에서는 남녀 모두 차이가 나타나지 않았다.

\section{무산소능력}

펜싱선수들의 무산소능력을 측정한 결과는 <Table $14>$ 와 같다. 남자 선수들의 경우, 평균파워의 절댓값에서 에페선수들이 플뢰레 선수보다 높았으며 $(p<.009)$, 여자선 수들의 경우 최고파워 $(p<.035)$ 와 평균파워 절댓값 $(p<.001)$ 
Table 13. Comparison of isokinetic leg strength $(60 \% \mathrm{sec})$ in sword category and gender

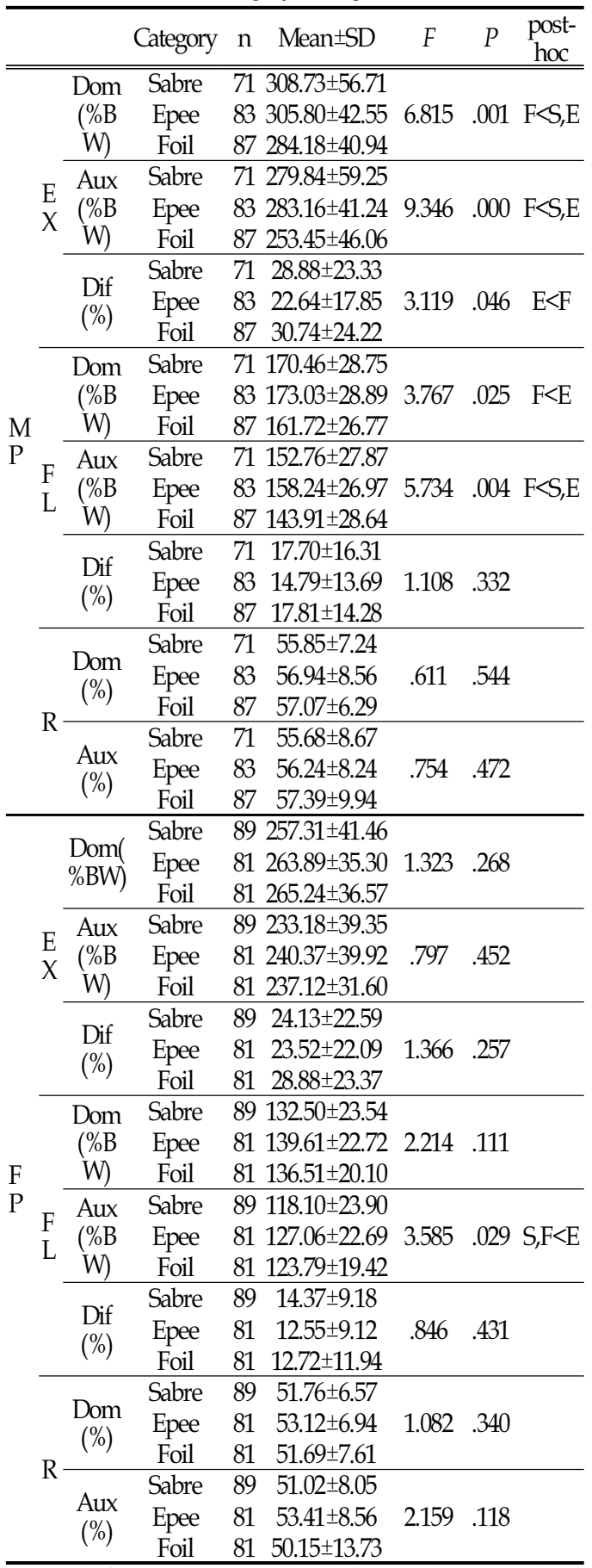

MP: male fencing player, FP: female fencing player, S: Sabre, E: Epee, F: Foil, EX: extensor, FL: flexor, R: ratio between Dom and Aux

Dom: dominant side, Aux: Auxiliary side, Dif: DiFPerence between Dom and Aux
Table 14. Comparison of anaerobic capacity in sword category and gender

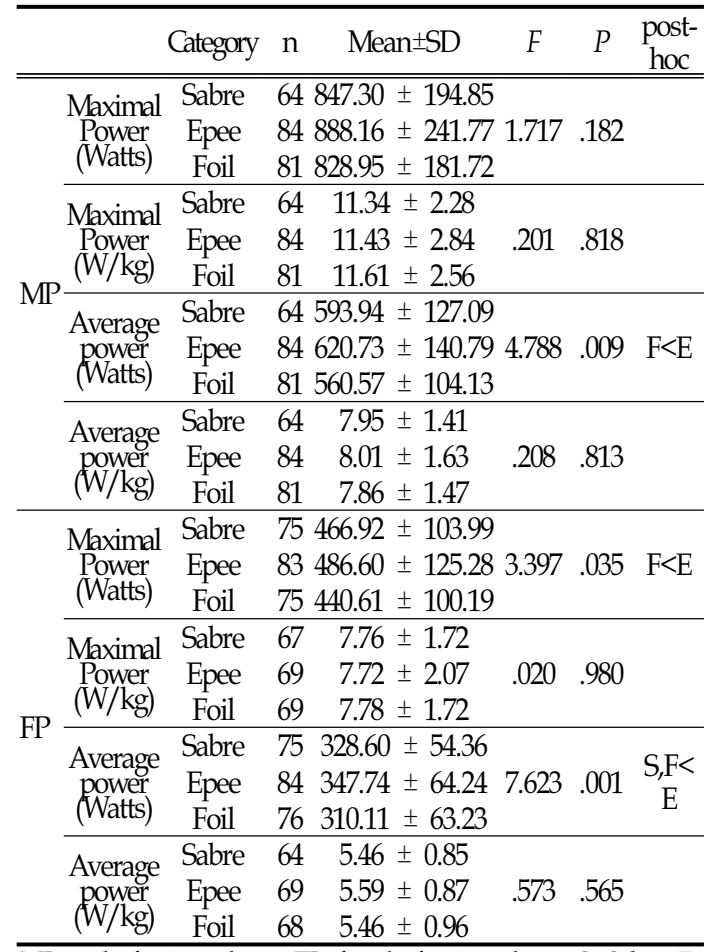

MP: male fencing player, FP: female fencing player, S: Sabre, E: Epee, F: Foil

에서 에페 선수들이 유의하게 높은 값을 나타냈다.

\section{논의}

본 연구는 엘리트 펜싱 선수의 성별 및 종목에 따라 체격 및 체력의 차이를 확인하여 펜싱 종목에 관한 특 성을 이해하고 선수 선발 및 훈련 프로그램의 개발하 는 데 기초자료로 활용하고 함에 그 목적이 있다.

스포츠 종목의 특성에 따라서 좋은 경기력 발휘를 위해 요구되는 체격과 체력에 차이가 있음을 보고한 연구는 적지 않다. 체격에 관한 연구들은 경기 수행 면에서 어떠한 신체적인 특성이 이점으로 작용하는가 를 확인하기 위하여 수행되었으며 이는 선수 선발에 서 중요한 요소로 활용된다.

본 연구 대상자의 신체적 특징을 살펴본 결과 우리나 라 국가 대표 펜싱선수 남.여 모두 신장은 외국 선수에 비해 떨어지지 않는 것으로 나타났다. Roi \& 
Bianchedi(2008)는 연구 대상자인 성인 펜싱 남자 선수 의 평균 신장은 $174 \pm 5 \mathrm{~cm} ~ 182 \pm 6 \mathrm{~cm}$, 여자 선수의 경우 는 $166 \pm 6 \mathrm{~cm}$ 정도로 보고하였는데, 우리나라 선수들도 신장 면에서 크게 뒤지지 않는 것으로 판단된다.

우리나라 남자 선수들의 경우는 에페 선수들이 신 장과 체중 등이 모두 제일 큰 것으로 나타났으며, 이 는 전신 공격이 가능한 에페의 특성과 맞는 결과라고 생각이 된다.

사브르의 경우 신장, 지극, 좌고 등 길이 면에서는 에페와 차이가 없고 플뢰레보다는 유의하게 크나 체 중이나 체지방률 등 신체구성 변인에서는 플뢰레와 차이가 없고 에페와 비교하면 유의하게 적은 것으로 나타나 우리나라 남자 사브르 선수들의 체형이 신장 에 비해 마른 편임을 확인할 수 있었다.

그러나 이런 결과는 외국 선수들과는 다소 차이가 있었는데, 국내 남자 선수의 경우 체중은 에페가 $77.80 \mathrm{~kg}$ 으로 가장 무겁고 그 다음이 사브르 $(73.81 \mathrm{~kg})$, 플뢰레 $(72.11 \mathrm{~kg})$ 순서였으나, 폴란드의 엘리트 선수의 경우 사브르 $(84.4 \mathrm{~kg}), \quad$ 에페 $(77.9 \mathrm{~kg})$, 플뢰레 $(74.9 \mathrm{~kg})$ 로 다른 경향을 나타냈다. 제지방량과 체질량지수 또한 국내 선수의 경우 에페가 사브르와 플뢰레 종목에 비 해 높게 나타났으나, 폴란드 선수의 경우 사브르가 에 페와 플뢰레에 비해 높게 측정되었으며, 이란 선수들 도 사브르 선수들의 체질량지수가 가장 큰 것으로 나 타났다(Sterkowicz, 2009; Abdollah et al., 2014).

여자 선수들도 길이와 신체구성면에서는 에페 선수 들이 사브르나 플뢰레보다 유의하게 큰 것으로 나타 났으며 사브르의 경우 플뢰레보다 유의하게 신체구성 변인이 높은 것으로 나타나 우리나라 여자 사브르 선 수들은 남자 선수들과는 달리 에페 선수들과 비슷한 경향을 보이는 것으로 생각된다. 이는 우리나라 사브 르 선수들이 날렵함보다는 파워 위주의 기술경기를 펼치는 것과 관련 있는 것으로 생각된다.

플뢰레 종목은 남녀 모두 체격이 가장 적은 것으로 나타났는데, 이는 플뢰레 종목이 타 종목보다 공격부 위가 작은 것과 관련이 있는 것으로 생각된다.

둘레 면에서도 남자 국외 엘리트 선수의 전완위 둘 레는 $27.62 \pm 2.19 \mathrm{~cm}$ 이며, 대퇴위 둘레는 $55.89 \pm 2.82 \mathrm{~cm}$ 로 국내 선수들보다 대퇴위 둘레는 적으나 전완위 둘 레는 비슷한 것으로 나타났다(Tsolakis et al., 2010).
대퇴의 둘레는 하지 근육과도 상관이 있는데(Arangio et al., 1997), 이는 우리나라 선수들이 하지를 많이 사 용하는 것과도 관련이 있는 것으로 볼 수 있다. 그러 나 반면 팔의 활용빈도가 떨어지기 때문에 이 부분은 추후 연구가 더 필요할 것으로 생각된다.

여자 선수들의 경우 홍콩 선수들과 비교해볼 때 16 18 세 여자 엘리트 선수들의 상완위 둘레는 $30.86 \pm 3.54 \mathrm{~cm}$, 하퇴위 둘레는 $39.58 \pm 3.43 \mathrm{~cm}$ 로 국내 여자 선수들과 비교 하면 하퇴위와 전완위 둘레 모두 높게 나타난 것을 확인 할 수 있었다(Teresa \& Education, 2013).

체력에 관한 연구들은 경기 수행력 향상을 위한 효 과적인 트레이닝 프로그램 개발을 위해 수행되었다고 할 수 있는데, 펜싱경기는 3 분 3 회전의 10 분 내외의 시합시간을 가지며 대부분 하루 안에 몇 번을 수행하 는 형태로 이루어지고 그 하루의 대부분은 휴식상태 로 대기하면서 몇 번의 시합을 준비하고 수행한다.

펜싱 숙련자를 대상으로 한 Milia 등(2013)의 연구 에 의하면 시합(대련) 중 나타난 운동강도는 환기역치 이하로 보고되었으며, 높은 수준의 유산소 능력보다는 마지막 3회전 이후의 회복에 초점을 맞춘 고강도 인 터벌 트레이닝이 필요하다고 제안하였다.

본 연구에서 심폐기능은 페활량(cc)과 1 초율(\%), 안 정시 심박수를 보았는데, 유의한 차이는 나타나지 않 았으나 남녀 플뢰레 종목의 선수들이 에뻬, 사브르 선 수들보다 페활량 및 1 초율이 낮은 것으로 나타났다.

플뢰레 선수들의 심폐기능이 다른 선수들에 비해 떨 어지는 것은 폐활량은 연령뿐만 아니라 신장의 영향을 받는다는 선행연구에 따라 관련이 있을 것으로 생각된 다(HEPPER et al., 1960). 그러나 플뢰레 선수들의 폐활 량도 다른 종목보다 크게 낮은 수치는 아니므로 종목의 특성상 크게 문제가 되지는 않으리라고 생각된다.

근력을 측정한 결과 남자는 하프 스쿼트와 악력, 여 자는 악력에서 에페 선수들이 다른 종목보다 유의하게 높은 것으로 나타났다. 근력은 체중과 관련이 있는 만 큼(Lawman et al., 2015) 에페 선수들이 다른 종목 선 수들에 비해 체중이나 제지방 체중이 우수했기 때문으 로 생각된다. 사브르와 플뢰레 간의 차이는 없었으나 하지근력의 경우는 사브르가 약간 높은 반면, 상지근 력의 경우는 플뢰레가 높은 것으로 나타나 종목 간의 차이가 다소 있는 것으로 생각된다. 플뢰레 종목은 찌 
르기 공격만 가능하며, 공격범위가 상반신의 몸통으로 제한되어 있으므로 검을 잡는 방법과도 관련이 있을 것으로 생각된다. 따라서 향후 검의 손잡이 유형과 함 께 추후 연구해볼 필요가 있을 것으로 생각된다.

근지구력 항목에서는 남자 선수들의 차이는 보이지 않았다. 하지만, 여자 선수의 경우 플뢰레 종목의 선 수들이 반복점프와 싯업에서 모두 유의하게 높은 결 과를 나타냈다. 근지구력은 에페 선수들이 유의하게 낮은 것으로 나타났는데 이는 근지구력이 체중과 체 지방률이 낮을수록 높게 나타난다는 선행연구와도 일 치하는 결과이다(Petrofsky \& Lind, 1975). 그러나 경 기의 특성상 플뢰레와 에페는 경기 시간이 사브르보 다 길어서 에페 선수들도 지구력을 기르기 위한 트레 이닝이 필요할 것으로 생각된다.

순발력 검사는 제자리멀리뛰기를 측정하였는데, 남 녀 모두 유의한 차이는 나타나지 않았다. 순발력의 경 우 종목의 특성상 빠른 공격이 요구되는 사브르 선수 들이 유의하게 높을 것으로 예측하였으나 유의한 차 이가 나지 않은 만큼 향후 남녀사브르 선수들의 순발 력을 높일 방안이 마련되어야 할 것으로 생각된다. 특 히 남자의 경우는 사브르 선수들의 순발력이 약간 높 았으나 여자의 경우는 플뢰레 선수들이 가장 높게 나 타났다. 이는 여자 사브르 선수들의 체격과도 관련이 있을 것으로 생각되나 여자 사브르 선수들의 순발력 향상을 위해 노력해야 할 것으로 생각된다.

민첩성의 경우 본 연구에서는 본 연구에서 남.여 모두 종목 간 차이를 보이지는 않았다. 펜싱은 $14 \mathrm{~m}$ 의 피스트 안에서 끊임없이 앞뒤로 움직여야 되는 만큼 민첩성이 매우 중요한 체력 요소이다. 이는 보디빌더, 역도, 레슬링 선수들의 민첩성을 비교한 결과 국가대 표 펜싱 남자선수들의 민첩성이 가장 높다고 보고한 Ahn \& Won(2003)의 선행연구에서도 확인할 수 있다. 민첩성에서는 남자 선수들의 경우 유의한 차이가 나 타나지 않았으나, 여자 선수들의 경우 30초간 발바꿔 뛰기에서 플뢰레 선수들이 에페 선수들보다 유의하게 높은 것으로 나타나 여자 에페 선수들의 민첩성을 올 릴 수 있는 트레이닝을 추가해야 할 것으로 생각된다.

유연성 검사에서는 남자 선수의 경우 장좌체전굴과 주측 발목각도, 여자 선수에서는 하지 좌우개각과 주 측발목 각도에서 종목 간 차이가 나타났다. 남자의 경
우 체전굴에서는 에페 선수들이 유의하게 높은 것으 로 나타났으나, 발목 각도는 가장 낮은 것으로 나타났 다. 이는 에페 종목의 특성상 전신을 공격해야 하므로 타 종목보다 유연성이 좋은 것으로 판단된다. 그러나 발목의 유연성이 낮은 만큼 부상의 위험이 있으므로 주의가 필요할 것으로 생각된다. 여자 선수들의 경우 하지 좌우개각에서 에페와 플뢰레의 유연성이 사브르 에 비해 좋은 것으로 나타났으며, 발목 가동범위도 사 브르가 가장 적은 것으로 나타났다. 펜싱에서 유연성 은 팡트나 프레시 등 여러 공격 동작에서 중요하다. 그러나 국가대표 펜싱 선수들의 유연성 평균은 비슷 한 동작을 수행하는 배드민턴선수들의 남자 $16.5 \mathrm{~cm}$, 여자 $22.5 \mathrm{~cm}$ 에 비해(Sung et al., 2014) 남자는 에페 선수들만, 여자는 플뢰레 선수들만 높은 것으로 나타 나 유연성 훈련이 필요할 것으로 생각된다.

그러나 평형성의 경우 사브르와 에페 선수들이 플뢰 레에 비해 높게 나타났다. 이는 비교적 가까이에서 공 격하는 플뢰레 종목의 특성상 나타난 결과라 생각되나 주측만 비교한 만큼 부상이나 골반 변위와도 비교한 추후 연구가 필요할 것으로 생각된다. 그러나 배드민턴 국가대표 선수들과의 비교에서, 국가대표 펜싱 남녀 선 수들이 종목과 상관없이 배드민턴 선수들보다 높게 측 정되었다(Sung et al., 2014). 동적 평형성은 움직이는 상황에서 얼마나 중심을 잘 잡고 있느냐 인데, 이 경우 에는 여자 에페 선수들이 사브르와 플뢰레보다 유의하 게 낮은 것으로 나타났다. 이는 에페 종목이 특히 여자 에서 사브르나 플뢰레보다 움직임이 적기 때문으로 생 각되며, 신장이 큰 만큼 손과 발을 활용해서 중심을 잡 는데 더 큰 집중력이 필요할 것으로 생각된다.

등속성 근력의 경우 남자 선수들은 신근과 굴근에 서 주측과 보조측 모두 플뢰레 종목의 선수가 다른 종목의 선수에 비해 유의하게 낮은 것으로 나타났다. 이는 플뢰레 종목의 선수가 사브르, 에페 종목의 선수 에 비해 신장과 체중이 작고, 종목의 특성상 파워가 덜 필요한 때문으로 생각된다. 반면 여자 선수의 경우 에는 신근에서는 차이가 나지 않았으나 굴근의 보조 측에서 에페 선수들의 근력이 플뢰레와 사브르 선수 에 비해 유의하게 높은 것으로 나타났다.

무릎의 굴근과 신근은 런지와 팡트 동작을 많이 하 는 펜싱 종목에서 매우 중요하다. 신근은 앞으로 나가 
며 공격할 때, 굴근은 후진하며 수비를 할 때 영향을 미치게 된다. 본 연구에서는 선수들의 주측과 보조측으 로 구분하여 비교한 만큼 다른 종목들과 정확한 비교 는 어렵지만 파워가 높은 것으로 알려진 육상투척 종 목 선수들과 비교하면 남녀 선수 모두 신근의 각근력 은 크게 낮지 않은 것으로 나타났다(Sung \& Lee, 2011). 또한 굴신비도 크게 문제가 되지는 않는 것으로 보인다. 그러나 주측과 보조측의 차이가 특히 신근에서 남녀 모든 종목에서 정상범위를 벗어나는 것으로 나타 났으며, 플뢰레 선수들은 에빼 선수들에 비해 통계적으 로도 유의하게 높은 것으로 나타나 부상예방을 위한 트레이닝 프로그램 마련이 필요할 것으로 생각된다.

무산소성 능력은 3분 3회전을 실시하는 펜싱 종목 에서 매우 중요한 체력요인으로 볼 수 있다. 본 연구 에서는 남자 선수의 경우 절대 평균파워, 여자의 경우 절대 최고파워와 평균파워에서 유의한 차이가 나타 났으나 상댓값에서는 차이를 나타내지 않았다. 이는 상대파워에서 종목별 차이가 나타나지 않았다는 이란 국가대표의 연구결과와 같은 결과이다(Abdollah et al., 2014). 그러나 펜싱 종목이 체급경기는 아닌 만큼 최고파워를 잘 활용할 경우 경기 결과에 긍정적 영향 을 미칠 수 있을 것으로 생각된다.

\section{결론}

선행연구들에 따르면, 같은 종목이라고 하더라도 세부 종목, 포지션, 또는 신장에 따라 전문체력의 차 이가 있다고 하였으며(Nebojša et al, 2011; Sung \& Lee, 2011), 본 연구에서도 그 차이를 확인할 수 있었 다. 남자선수의 경우 에뻬 종목 선수가 신체구성 및 체격이 큰 것으로 나타났으며, 이에 따라 근력 및 유 연성이 우수한 것으로 나타났다. 반면 플뢰레 종목의 선수는 체격이 작았으나 근지구력이 우수한 것으로 나타났다. 체격에서 주목할 만한 것은 남자의 경우 사 브르 종목 선수, 여자의 경우 에뻬 종목 선수가 체격이 크고 다소 마른 것으로 나타났다. 따라서 펜싱의 기술 개발에서 이러한 체격 및 체력의 차이점을 고려하여 보다 과학적이고, 개별화된 훈련프로그램을 제공할 수
있을 것이며, 또한 우수선수 선발 및 종목 배정에도 참고자료로 활용이 가능할 것으로 판단된다.

\section{참고문헌}

Abdollah, S., Khosrow, E, \& Sajad, A. (2014). Comparison of Anthropometric and Functional Characteristics of Elite Male Iranian Fencers in Three Weapons. International Journal of Applied Sports Sciences, 26(1).

Ahn, Y. D., \& Won, Y. D. (2003). effects of Exericse Characteristics by Items on Body Composition and Physical Fitness of Weight Competition Athletes. Journal of Kora Sport Research, 14(4): 1327-1338.

Arangio, G. A., Chen, C., Kalady, M., \& Reed III, J. F. (1997). Thigh muscle size and strength after anterior cruciate ligament reconstruction and rehabilitation. Journal of Orthopaedic \& Sports Physical Therapy, 26(5): 238-243.

Barth B., \& Beck E. (2007). The complete guide to fencing. Oxford: Meyer and Meyer sport (UK) Ltd.

CRONIN, J., MCNAIR, P. E T. E. R, \& MARSHALL, R (2003). Lunge performance and its determinants. Journal of Sports Sciences, 21(1): 49-57.

HEPPER, N. G., FOWLER, W. S., \& HELMHOLZ, F. (1960). Relationship of height to lung volume in healthy men. Diseases of the Chest, 37(3): 314-320.

Kim, D. H. (2010). National Analysis of Attack Points in the Fencing Sabre. Journal of Kora Sport Research, 21(1): 53-63.

Kim, J. J., Park, C. H. (1995). Comparative research about the characteristic on physique and physical fitness of each sports -To substance of sports in K-university-. The Journal of Physical Education, 23: 107-119

Kim, T. W. (2011). Sports Field: 2010 The Soaring 
Korean Fencing. Sports Science, 114: 63-68.

Kim, T. W. (2012). Introduction of National Fencing Team Support System on London Olympic. Proceeding of Korea Association of Certified Exercise Professionals Workshop, 36: 23-26.

Kim, Y. S., Kim, J. S., \& Kim, C. B. (2004). The Anaysis of Game Technical Pattern in Fencing of Modern Pentathlon. Koran Journal of Sport Science, 15(4): 195-205.

Kim, Y. S., Ko, B. G., Kim, K. J., Kim, J. H., Sung, B. J., Yoon, S. W., \& Eom, H. J. (2007). KISS Physical Fitness Test and Evaluation Manual: Focus on Measurement instruments of Sports Performance Estimation Program. Korea Sports Promotion Foundation Korea Institute of Sports Science.

Lawman, H. G., Troiano, R. P., Perna, F. M., Wang, C. Y., Fryar, C. D., \& Ogden, C. L. (2015). Associations of Relative Handgrip Strength and Cardiovascular Disease Biomarkers in US Adults, 2011-2012. American journal of preventive medicine.

Milia, R., Roberto, S., Pinna, M., Palazzolo, G., Sanna, I., Omeri, M., \& Crisafulli, A. (2013). Physiological responses and energy expenditure during competitive fencing. Applied Physiology, Nutrition, and Metabolism, 39(3), 324-328.

Mun, Y. M., Kim, M. H., Choi, M. D. (1998). The characteristic ananlysis of physique, body composition and physical fitness according to sports. The Korean Journal of Growth and Development, 6: 5471.

Nebojša Trajkovic., Zoran M, Goran Sporiš., \& Milivoje Radisavljevic. (2011). Positional diFPerences in body composition and jumping performance among youth elite volleyball players. Acta Kinesiologica, 5(1): 62-66.

Oh, C. H., Bae, J. H., Shin, E. S., Hong, S. Y., Choi, J. K., \& Lee, J. T. (2013). A kinetics analysis fo Fente Motion in Eppe Game of Women's Fencing players. The Korea Journal of Sports Science, 22(4): 1273-1283.

Park, J. C., Kim, T. W., Song, J. H., Back, J. H., \& Kim, T. G. (2011). Effects of Patellar Tendinopathy on the Marche-fente Movement of Femal Fencing Fleuret Players. Koran Journal of Sport Science, 22(2): 1875-1883.

Petrofsky, J. S., \& Lind, A. R. (1975). The relationship of body fat content to deep muscle temperature and isometric endurance in man. Clinical science and molecular medicine, 48(5): 405-412.

Roi, G. S., \& Bianchedi, D. (2008). The science of fencing. Sports Medicine, 38(6): 465-481.

Shin, B. C, Yoo, J. M, Choi, T. S., Park, J. H, \& Kim, H. J. (2003). Discriminant Analysis by Anthropometric Variable on Elite Fencing Players. Journal of Kora Sport Research, 14(4): 1261-1270.

Shin, B. C., Choi, T. S., Kim, C. H., Kim, H. J., \& Choun, Y. H. (2006). Anthropometric Traits and Genetic Distribution Between Successive and Non-successive Elite Fencers. Journal of Kora Sport Research, 17(5): 623-632.

Sterkowicz-Przybycien, K. (2009). Body composition and somatotype of the elite of Polish fencers. Collegium antropologicum, 33(3): 765-772.

Sung, B. J., \& Lee, Y. S. (2011). An Examination of Basic and Specific Fitness of Elite National Throwing Athletes (Javelin, Shot put, Discus, Hammer Throwers). Koran Journal of Sport Science, 22(3): 2220-2236.

Sung, B. J., Lee, J. Y., \& Lee, D. S. (2014). Comparison on Basa Physical Fitness and Badminton Smash Spedd of Korea National Badminton Player in Male and Female. Koran Journal of Sport Science, 25(2): 364-373.

Teresa, M., \& Education, P. (2013). Anthropometric characteristics of senior secondary school female shot put athletes in Hong Kong. 
Trajkovic, N., Milanovic, Z., Sporis, G., \& Radisavljevic, M. (2011). Positional differences in body composition and jumping performance among youth elite volleyball players. Acta Kinesiologica, 5(1): 62-66.

Tsolakis, C., Kostaki, E., \& Vagenas, G. (2010). Athropometric, flexibility, strength-power, and sport-specific correlates in elite fencing1. Journal Information, 110(3C): 1015-1028.

Tsolakis, C., Bogdanis, G. C., Nikolaou, A., \& Zacharogiannis, E. (2011). Influence of type of muscle contraction and gender on postactivation potentiation of upper and lower limb explosive performance in elite fencers. Journal of sports science $\mathcal{E}$ medicine, 10(3): 577.

Turner, A, James, N., Dimitriou, L., Greenhalgh, A, Moody, J., Fulcher, D., Mias, E., \& KilduFP, L. (2014). Determinants of Olympic Fencing
Performance and Implications for Strength and Conditioning Training. The Journal of Strength \& Conditioning Research, 28(10): 3001-3011.

Ulrich, R., \& Egbert, L. (2012). Teaching Olympic Fencing to the Deaf: Identifying and Addressing a Gap in Teaching the Sport. International Journal of Sport \& Society, 3(4).

West, D. J., Owen, N. J., Jones, M. R., Bracken, R. M., Cook, C. J., Cunningham, D. J., \& Kilduff, L. P. (2011). Relationships between force-time characteristics of the isometric midthigh pull and dynamic performance in professional rugby league players. The Journal of Strength $\&$ Conditioning Research, 25(11): 3070-3075.

Woo, B. W., Kwon, T. D., \& Huh, M. D. (1997). An Analysis on Basic Physical and Muscular strength of Fencing Athletes. Journal of the humanities, 16: 307-317. 